\title{
High prevalence of cardiovascular risk factors in children and adolescents with Williams-Beuren syndrome
}

\author{
Daiji Takeuchi ${ }^{1 *}$, Michiko Furutani ${ }^{1,2}$, Yuriko Harada ${ }^{1,2}$, Yoshiyuki Furutani $^{1,2}$, Kei Inai ${ }^{1}$, Toshio Nakanishi ${ }^{1,2}$ \\ and Rumiko Matsuoka $a^{1,2,3^{*}}$
}

\begin{abstract}
Background: A high incidence of cardiovascular (CV) risk factors has been reported in adults with Williams-Beuren syndrome (WS). However, the prevalence of these factors in children and adolescents with WS is unknown. Therefore, the purpose of this study was to evaluate the prevalence of $\mathrm{CV}$ risk factors in these patients.

Methods: Thirty-two WS patients aged $<18$ years were enrolled in the study. Oxidized low-density lipoprotein levels ( $n=32)$, oral glucose tolerance test results $(n=20)$, plasma renin and aldosterone levels $(n=31), 24-h$ ambulatory blood pressure (ABP; $n=24)$, carotid artery intima-media thickness (IMT; $n=15)$, and brachial artery flow-mediated dilatation (FMD; $n=15$ ) were measured and analyzed.

Results: The lipid profile revealed hypercholesterolemia in $22 \%$ and elevated oxidized low-density lipoprotein levels in $94 \%$ of the patients. Glucose metabolism abnormalities were found in $70 \%$ of the patients. Insulin resistance was observed in $40 \%$ of the patients. High plasma renin and aldosterone levels were detected in 45 and $39 \%$ of the patients, respectively. A mean systolic blood pressure above the 90 th percentile was noted in $29 \%$ of patients. High IMT $(>0.65 \mathrm{~mm})$ and low FMD (<9\%) were detected in 80 and $73 \%$ of patients, respectively.

Conclusion: In patients with WS, CV risk factors are frequently present from childhood. In children with WS, screening tests for the early detection of $\mathrm{CV}$ risk factors and long-term follow-up are required to determine whether long-term exposure to these factors increases the risk for $\mathrm{CV}$ events in adulthood.
\end{abstract}

Keywords: Williams-Beuren syndrome, Cardiovascular risk, Child, Adolescent, Elastin

\section{Background}

Williams-Beuren syndrome (WS) was first described in 1961 by Williams et al. [1]. They reported four patients with supravalvular aortic stenosis (SVAS), mental retardation, and characteristic facial features. At present, WS is recognized as a congenital developmental disorder involving the connective tissue and central nervous system, and it is accompanied by various characteristic facial features. The syndrome is characterized by growth delay, mental retardation with typical neurobehavioral profile [2], cardiovascular (CV) abnormalities, hypertension, hypercholesterolemia, hypothyroidism, and occasional

\footnotetext{
* Correspondence: ptakeuci@hij.twmu.ac.jp; rumiko@imcir.twmu.ac.jp

'Department of Pediatric Cardiology, Tokyo Women's Medical University, 8-1 Kawada-cho, Shinjuku-ku, Tokyo 162-8666, Japan

Full list of author information is available at the end of the article
}

infantile hypercalcemia. In 1993, Ewart et al. [3] reported that haploinsufficiency of multiple genes, including microdeletions of the elastin gene locus at $7 q 11.23$, contribute to the phenotypic features of WS. Loss of elastin function is responsible for the associated CV abnormalities [4]. In adult WS patients, CV risk factors such as diabetes mellitus, hypertension, and hyperlipidemia are frequently present [5]. The prevalence of these risk factors among children with WS remains unknown; however, we hypothesize that they are present from a young age. A high prevalence of $\mathrm{CV}$ risk factors in childhood would likely contribute to $\mathrm{CV}$ events during adulthood. The purpose of this study was to evaluate the incidence of such factors, including hypercholesterolemia, impaired glucose tolerance, high blood pressure, renin-angiotensin-aldosterone (RAA) activation, intima-media thickness (IMT) of the carotid 
artery, and endothelial dysfunction in children and adolescents with WS; this is an important step in the prevention of future CV events in WS patients.

\section{Methods}

We studied 32 WS patients aged $<18$ years. Fluorescence in situ hybridization (FISH) was performed using the following 6 probes: PAC537N8 (WSTF and FZD9), BAC27H2 (STX1A), WSCR (ELN), PAC 117G9 (LIMK1), BAC363B4 (RFC2, CYLN2), and BAC1184P14 (GTF2I), which included 8 genes for detecting microdeletions on chromosome 7q11.23, as previously reported [6]. A typical deletion was revealed in 26 patients, and an atypical shorter deletion was discovered in 6 (Fig. 1). The following laboratory measurements were obtained: (1) a plasma lipid profile that included oxidized low-density lipoprotein (oxLDL) ( $n=32)$ and lipoprotein-a (Lipo(a); $n=32)$; (2) glucose levels (via the oral glucose tolerance test (OGTT; $n=20)$; (3) plasma renin and aldosterone levels $(n=31)$;
(4) 24-h ambulatory blood pressure (ABP; $n=24)$; (5) carotid artery IMT $(n=15)$; and (6) brachial artery flow-mediated dilatation (FMD; $n=15$ ). All biochemical measurements in this study were performed using commercially available kits. The OxLDL and malondialdehyde-modified low-density lipoprotein (MDA-LDL) levels were measured (oxLDL, Kyowa Medics, Japan; $n=13$ and MDA-LDL enzyme-linked immunosorbent assay, SRL, Japan; $n=19$ ). A high oxLDL level was defined as oxLDL $>7 \mathrm{U} / \mathrm{L}$ (normal: $<6.9 \mathrm{U} / \mathrm{L}$ ) or MDA-LDL $>38.3 \mathrm{U} / \mathrm{L}$ (normal: $<38.2 \mathrm{U} / \mathrm{L}$ ) in patients aged $<18$ years. Lipo(a) was also measured (SRL, Japan), and a high Lipo(a) level was defined as a level of $>40 \mathrm{mg} / \mathrm{dL}$ (normal: $<39 \mathrm{mg} / \mathrm{dL}$ ). The standard 2-h OGTT was performed in 20 patients with no history of diabetes, with the results classified according to the guidelines of the American Diabetes Association. Impaired fasting glucose level was defined as a glucose level of $100-125 \mathrm{mg} / \mathrm{dL}$, and impaired glucose tolerance was defined as a plasma glucose level of $140-199 \mathrm{mg} / \mathrm{dL} 2 \mathrm{~h}$

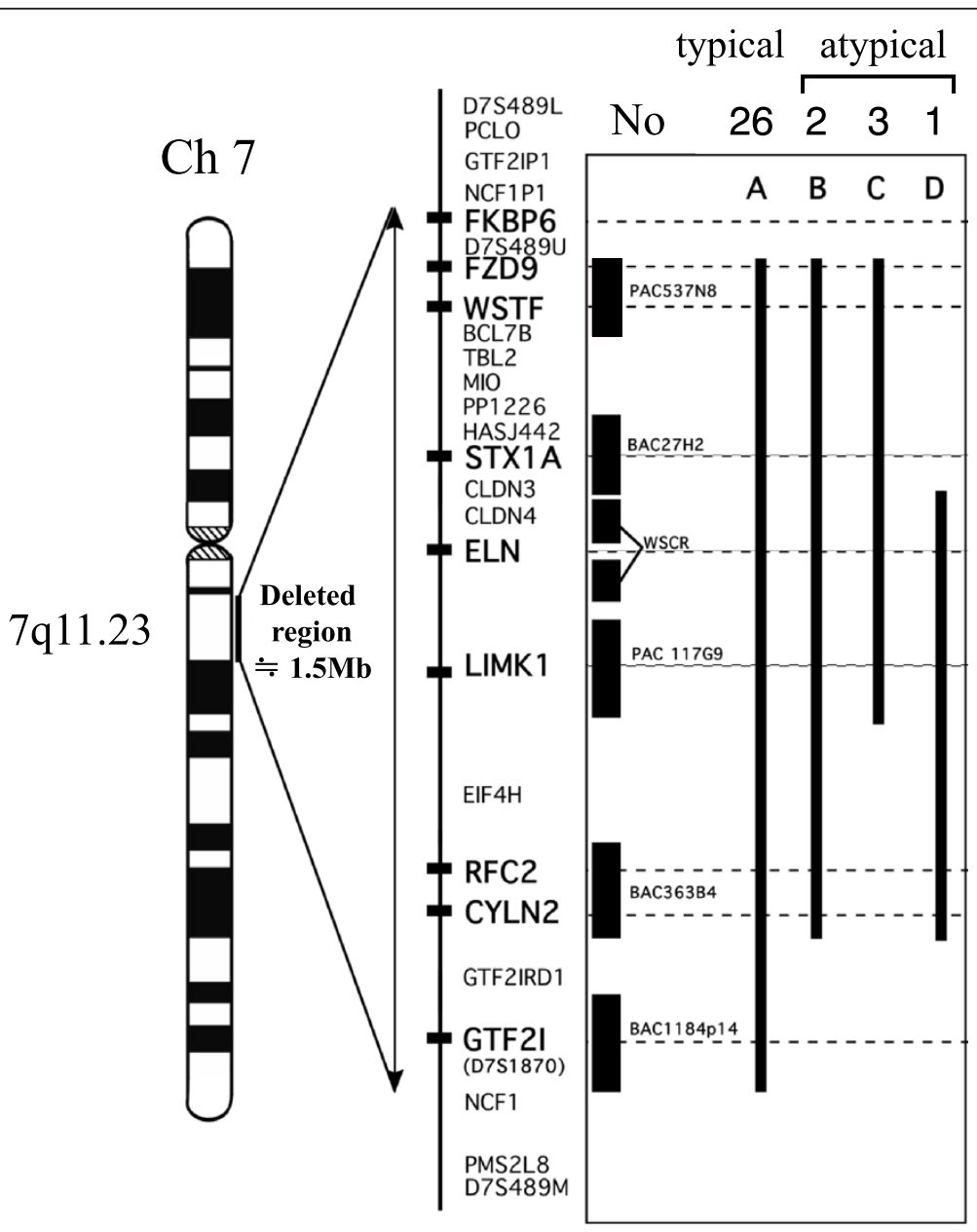

Fig. 1 The chromosome 7q11.23 microdeletion was associated with the Williams-Beuren syndrome phenotypes in all subjects. Overall, 26 of 32 patients (82 \%) showed the typical deletion responsible for Williams-Beuren syndrome (denoted as A), and 6 patients showed atypical deletions shorter than $\mathrm{A}(\mathrm{B}, n=2 ; \mathrm{C}, n=3$; and $\mathrm{D}, n=1)$ 
after OGTT. Type 2 diabetes was defined as a fasting glucose level of $\geq 126 \mathrm{mg} / \mathrm{dL}$ or a 2 -h plasma glucose level of $>200 \mathrm{mg} / \mathrm{dL}$ [7]. The homeostasis model assessment insulin resistance index (HOMA-IR) was also measured, with insulin resistance defined as HOMA-IR $>2$. Impaired insulin secretion was defined as an insulinogenic index $<0.4$. Plasma levels of active renin were measured (PRA, SRL, Japan, respectively), and elevated renin levels were defined as levels $>3 \mathrm{pg} / \mathrm{mL}$ (normal range: 0.3-2.9 $\mathrm{pg} / \mathrm{mL}$ ). Plasma levels of aldosterone were measured (Aldosterone RIA kit II; Dinabot, Japan; $n=15$ or SPAC-S Aldosterone Kit; TFB, Japan; $n=17$ ). Elevated aldosterone levels were defined as levels $>15 \mathrm{ng} / \mathrm{dL}$ (normal range: 2.2-14.9 $\mathrm{ng} / \mathrm{dL}$ ) and $>159 \mathrm{pg} / \mathrm{mL}$ (normal range: $29.9-$ $158 \mathrm{pg} / \mathrm{mL}$ ) as measured using the SPAC-S aldosterone kit and RIA kit II, respectively. On the basis of ABP, high blood pressure (BP) was defined as a mean daytime BP above the 90th percentile corrected by sex, age, and height, as previously reported [8].

For IMT assessment, both common carotid arteries were measured in the longitudinal plane from the level of the clavicles to the carotid bifurcation, as previously reported [9]. Abnormal thickening was defined as IMT $>0.65 \mathrm{~mm}$ in individuals aged $<18$ years [9-11]. FMD was measured in the right brachial artery after sublingual administration of nitroglycerin, in order to determine the extrinsic nitric oxide donor (nitroglycerin)-induced dilatation (NID), as previously reported [12]. Low FMD was defined as FMD < $9 \%$, and low NID was defined as FMD $<12 \%$. Ethical approval for this study was granted by the institutional review board of the Tokyo Women's Medical University Hospital, Japan. Informed consent was obtained from the participants themselves or their parents in the case of children aged $<16$ years.

\section{Statistical analysis}

Data are expressed as median (range) or mean \pm standard deviation. Comparisons between the two groups were performed using the unpaired $t$-test or Mann-Whitney $U$-test. Pearson's correlation coefficient was used to assess the associations between the two groups. Values were considered significantly different at $p<0.05$. All analyses were performed using the JMP statistical software (version 11; SAS Institute, Cary, NC).

\section{Results}

In the $32 \mathrm{WS}$ patients, the median age of the subjects was 9.1 years (range, 1.3-17.9 years). The male: female ratio was 1:1.5, and the median height, body weight, and body mass index (BMI) were $122 \mathrm{~cm}$ (range, 78-147 cm), $25 \mathrm{~kg}$ (range, 6-41 kg) and 15.4 (range, 10.0-22.8), respectively. A BMI $>22$ was observed in only 1 patient ( $3 \%)$.

\section{Cardiovascular abnormalities}

CV abnormalities were observed in 29 out of 32 patients (91 \%). Among these, 24 patients had SVAS. The details of $\mathrm{CV}$ abnormalities are shown in Table 1. Five patients underwent surgical intervention for these abnormalities. Repair of the SVAS and ligation of patent ductus arteriosus had been performed previously in 4 and 1 patients, respectively. At the time of the study, no patient showed SVAS with an estimated pressure gradient of $>50 \mathrm{~mm} \mathrm{Hg}$ between the left ventricle and ascending aorta, as measured by echocardiography or cardiac catheterization. One patient had moyamoya disease.

\section{Lipid profile}

The results of lipid profile testing are shown in Table 2. Overall, $92 \%(23 / 25)$ of the patients without hypercholesterolemia had high levels of oxLDL. The median level of total cholesterol, oxLDL, MDA-LDL, Lipo(a), highdensity lipoprotein-cholesterol, and triglycerides were $166 \mathrm{mg} / \mathrm{dL}$ (range, 86-236 mg/dL),12.6 U/L (range, 7.5-46.6 U/L), 62.6 U/L (range, 28.6-116.0 U/L), $11 \mathrm{U} / \mathrm{L}$ (range, 3-99 U/L), $62 \mathrm{mg} / \mathrm{dL}$ (range, 34-96 mg/dL), and $51 \mathrm{mg} / \mathrm{dL}$ (range, 33-116 mg/dL), respectively. There was no significant correlation between oxLDL levels and BMI. The results for the various parameters are summarized in Table 3.

\section{Impaired glucose metabolism}

In this study, 14 patients demonstrated impaired glucose tolerance. Four and 10 of these patients were subsequently diagnosed with diabetes and impaired glucose tolerance, respectively. The median fasting blood sugar and insulin levels were $94 \mathrm{mg} / \mathrm{dL}$ (range, 80-103 mg/dL)

Table 1 Summary of the cardiovascular abnormalities of the 32 patients

\begin{tabular}{ll}
\hline & Number \\
\hline SVAS alone & 7 \\
SVAS with MVP & 6 \\
SVAS with pulmonary stenosis & 5 \\
SVAS with ventricular septal defect & 2 \\
SVAS with MVP and PAPVR & 1 \\
SVAS with MVP and pulmonary stenosis & 1 \\
SVAS with coarctation of the aorta & 1 \\
SVAS with a bicuspid aortic valve & 1 \\
MVP alone & 3 \\
MVP with patent ductus arteriosus & 1 \\
Pulmonary stenosis & 1 \\
None & 3 \\
\end{tabular}

SVAS: supravalvular aortic stenosis, MVP: mitral valve prolapse, PAPVR: partial anomalus pulmonary venous return 
Table 2 Summary of lipid profile test

\begin{tabular}{ll}
\hline & Number (Percentage) \\
\hline Lipid profile $(n=32)$ & $7(22 \%)$ \\
Hypercholesterolemia & $30(94 \%)$ \\
High oxidized LDL & $6(19 \%)$ \\
High Lipo (a) & $1(3 \%)$ \\
Hypertriglyceridemia & $2(6 \%)$ \\
Low high-density lipoprotein cholesterol &
\end{tabular}

LDL: low-density lipoprotein

and $7.5 \mu \mathrm{U} / \mathrm{mL}$ (range, $0.2-13.7 \mu \mathrm{U} / \mathrm{mL}$ ), respectively. The insulinogenic index was 0.8 (range, $0.2-1.2$ ) and the HOMA-IR was 1.8 (range, 0.03-3.1). The glycated hemoglobin level was $<6.2 \%$ in all patients, with a median level of $4.8 \%$ (range, 4.6-5.0 \%). A BMI of $>22$ was observed in only 1 patient.

\section{Plasma renin and aldosterone activation}

The median plasma renin level was $2.6 \mathrm{pg} / \mathrm{mL}$ (range, $0.3-13.0 \mathrm{pg} / \mathrm{mL}$ ). The median plasma aldosterone level measured using the RIA kit II was $10.1 \mathrm{ng} / \mathrm{dL}$ (range, $5.2-22.9 \mathrm{ng} / \mathrm{dL}$ ) and that measured using the SPAC-S kit was $165 \mathrm{pg} / \mathrm{mL}$ (range, $57.3-393 \mathrm{pg} / \mathrm{mL}$ ).

\section{Ambulatory blood pressure monitoring}

The median daytime BP in all subjects was $116 \mathrm{~mm} \mathrm{Hg}$ (range, 100-131 mm Hg). The median daytime BP was $126 \mathrm{~mm} \mathrm{Hg}$ (range, 120-147 $\mathrm{mm} \mathrm{Hg}$ ) and $109 \mathrm{~mm} \mathrm{Hg}$ (range, 103-119 $\mathrm{mm} \mathrm{Hg}$ ) in the hypertensive and nonhypertensive groups, respectively. The BMI was not

Table 3 Summary of the results of various parameters

\begin{tabular}{ll}
\hline & Number (Percentage) \\
\hline Glucose tolerance $(n=20)$ & $2(10 \%)$ \\
Impaired fasting glucose & $14(70 \%)$ \\
Impaired glucose tolerance or DM by OGT & $8(40 \%)$ \\
Insulin resistance (HOMA-IR>2) & $3(15 \%)$ \\
Impaired insulin secretion & \\
Renin-aldosterone system ( $n=31)$ & $14(45 \%)$ \\
Increased plasma renin level & $12(39 \%)$ \\
Increased plasma aldosterone & \\
Ambulatory blood pressure monitoring $(n=24)$ & $7(29)$ \\
High blood pressure $>90$ percentile & \\
Carotid artery ultrasound $(n=15)$ & $12(80 \%)$ \\
Increased IMT (>0.65 mm) & \\
Endothelial dysfunction $(n=15)$ & $11(73 \%)$ \\
FMD <9 \% & $2(13 \%)$ \\
NG-induced dilatation <12 \% &
\end{tabular}

OGT: oral glucose tolerance test, DM: diabetes mellitus, HOMA-IR: homeostasis model assessment insulin resistance, IMT: intima-media thickness of the carotid artery, FMD: flow-mediated dilatation of the brachial artery, NG: nitroglycerin significantly different between the hypertensive and nonhypertensive groups (15.8 [14.4-18.0] vs. 16.1 [13.4-22.8], respectively).

\section{IMT of the carotid artery}

The median IMT of the right and left carotid artery was $0.73 \mathrm{~mm}$ (range, $0.50-0.90 \mathrm{~mm}$ ) and $0.71 \mathrm{~mm}$ (range, $0.50-0.90 \mathrm{~mm}$ ), respectively. A high IMT in at least one carotid artery $(>0.65 \mathrm{~mm})$ was observed in $80 \%$ of patients $(12 / 15)$. The median IMT of the right carotid artery was $0.70 \mathrm{~mm}$ (range, $0.60-0.79 \mathrm{~mm}$ ) and $0.73 \mathrm{~mm}$ (range, $0.50-0.90 \mathrm{~mm}$ ) in the hypertensive and the nonhypertensive groups, respectively. The median IMT of the left carotid artery was $0.70 \mathrm{~mm}$ (range, $0.60-0.89 \mathrm{~mm}$ ) and $0.71 \mathrm{~mm}$ (range, $0.50-0.90 \mathrm{~mm}$ ) in the hypertensive and nonhypertensive groups, respectively. There were no significant differences in IMT between the hypertensive and nonhypertensive groups. There were also no significant correlations between age and IMT (left IMT: $R=-0.02$; right IMT: $R=-0.04$ ) or SVAS pressure gradients estimated using echocardiography and IMT $(R=0.3)$. The relationship between IMT of the carotid artery and age is summarized in Fig. 2a and 2b.

\section{FMD of the brachial artery}

The median FMD was $5.6 \%$ (range, 0-18.2 \%), and low FMD $(<9 \%)$ was detected in $73 \%(11 / 15)$ of the patients. The median level of NID was $16 \%$ (range, 7.1-25.9\%), and low NID $(<12 \%)$ was observed in $13 \%(2 / 15)$ of the patients. The mean FMD was $4.3 \% \pm 3.2 \%$ and $7.4 \% \pm$ $1.6 \%$ in the hypertensive and nonhypertensive groups, respectively. The mean FMD between groups was not significantly different. There were also no significant correlations between BMI and FMD $(R=0.02)$, age and FMD $(R=-0.13)$, or age and NID $(R=-0.15)$. The relationship between FMD or NID of the brachial artery and age is summarized in Fig. 3a and 3b.

\section{Hypertension}

There were no differences in any of the study measurements between the hypertensive and non-hypertensive groups.

\section{Deletions}

Results of the chromosome $7 q 11.23$ microdeletion associated with the phenotypes in all WS patients are demonstrated in Fig. 1. Differences in the various parameters between the WS patients and the typical and atypical deletions are summarized in Table 4. Plasma renin and aldosterone levels measured by SPAC-S in patients with typical deletions $(n=26)$ were higher compared to those in patients with atypical deletions $(n=6)$. There were no significant differences in lipid profiles, impaired glucose metabolism, hypertension, IMT, and 

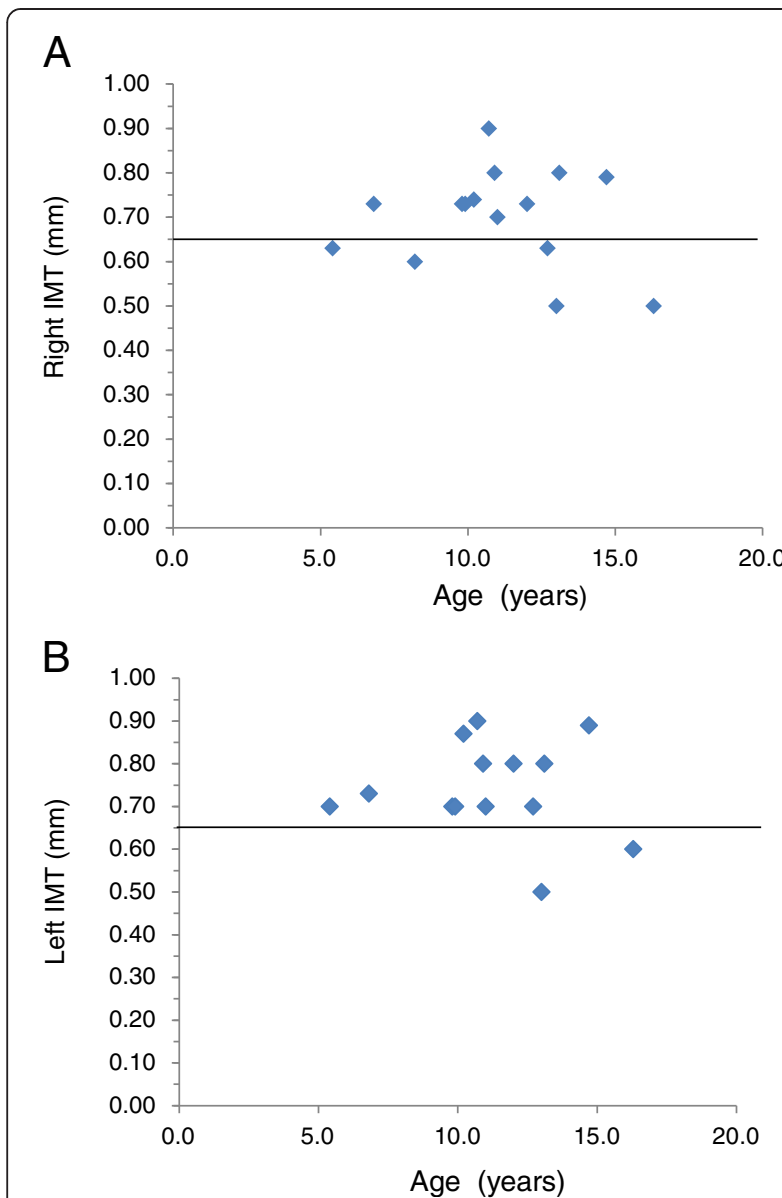

Fig. 2 Relationship between intima-media thickness (IMT) of the carotid artery and age. a The right carotid artery and (b) the left carotid artery. Line indicates IMT $=0.65 \mathrm{~mm}$, suggesting the upper limit in individuals aged below 18 years

endothelial function between patients with typical deletions and those with atypical deletions.

\section{Discussion}

Decreased elastin function is known to be the underlying etiology for the cardiovascular lesions found in WS [10, 13-16]. In adult patients, a high prevalence of $\mathrm{CV}$ risk factors such as diabetes, hypertension, and hypercholesterolemia has been reported [5, 17-19]. However, the prevalence of such risk factors in children with WS has not been well studied. Risk stratification in children and adolescents is important, because a clear translation of $\mathrm{CV}$ risk factors in children into adulthood is expected to increase the incidence of future CV events [20]. As part of a holistic molecular genetic medicine approach [21] in this study, we evaluated the incidence of $\mathrm{CV}$ risk factors, including impaired glucose intolerance, hyperlipidemia, an activated renin-aldosterone system, endothelial dysfunction, and high IMT among children with WS.
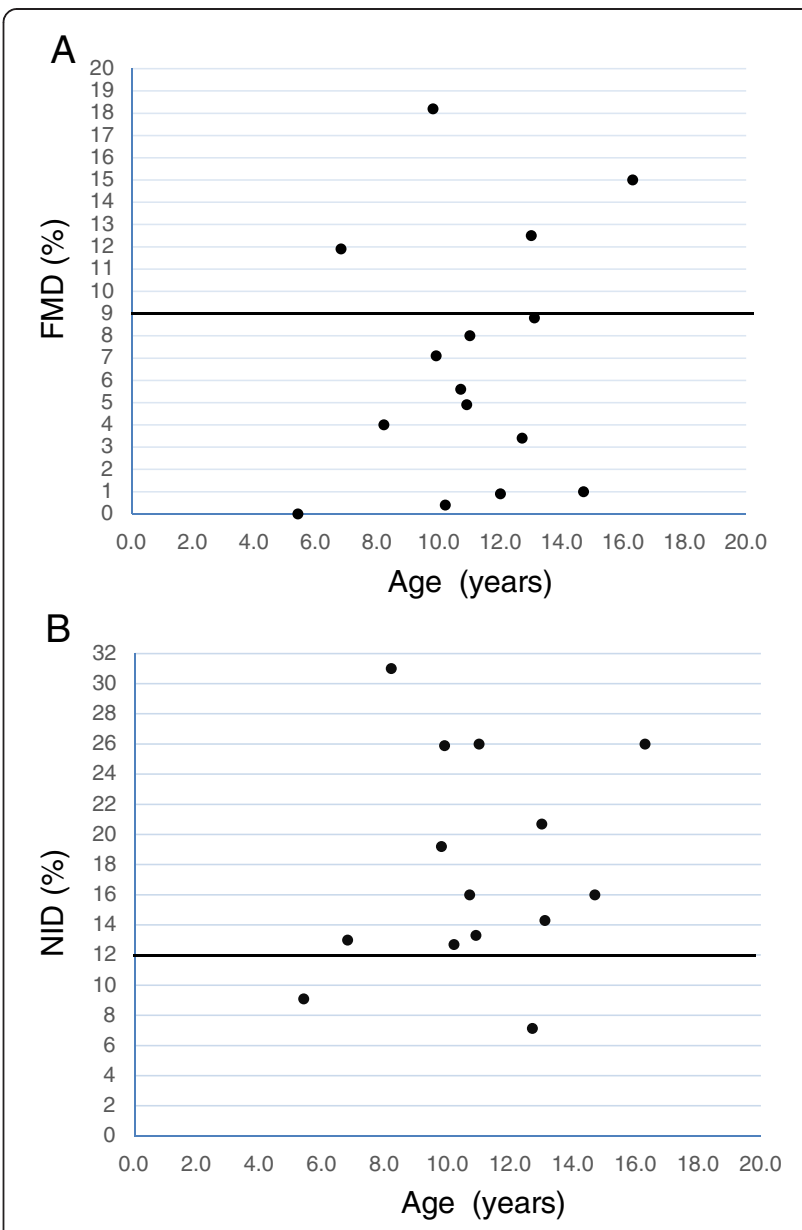

Fig. 3 a Relationship between flow-mediated dilatation (FMD) of the brachial artery and age. Line indicates FMD $=9 \%$, suggesting the lower limit of FMD. $\mathbf{b}$ Relationship between extrinsic nitric oxide donor-induced dilatation (NID) of the brachial artery and age. Line indicates NID $=12 \%$, suggesting the lower limit of NID

\section{Hyperlipidemia and impaired glucose tolerance}

In our study, $22 \%$ of the patients had hypercholesterolemia. Interestingly, $92 \%(22 / 25)$ of the patients without hypercholesterolemia demonstrated elevated levels of oxLDL. Oxidation of LDL is believed to be important in the development of early atherosclerosis, and oxLDL possesses several biologic properties that may promote atherogenesis [22, 23]. The OGTT results revealed that $70 \%$ of the patients had impaired glucose tolerance or diabetes, which is consistent with the findings of previous studies on adult WS [5, 17-19, 24]. In this study, the high prevalence of elevated HOMA-IR revealed that hidden insulin resistance is present from childhood in WS patients. Both insulin resistance and an increased production of oxLDL may be associated with the progression of atherosclerosis in WS. Conversely, the elastin peptide that is derived from the degradation of elastin induces the oxidation of LDL by phagocytic cells and thereby promotes the initiation and progression of the atherosclerotic 
Table 4 Differences in various clinical and laboratory parameters between the typical and atypical deletion groups

\begin{tabular}{|c|c|c|c|}
\hline & $\begin{array}{l}\text { Typical deletion } \\
\text { (total } n=26 \text { ) }\end{array}$ & $\begin{array}{l}\text { Atypical deletion } \\
(\text { total } n=6)\end{array}$ & $P$ value \\
\hline Age (year) & $9.4 \pm 4.2$ & $8.3 \pm 4.9$ & NS \\
\hline Male & $9(35 \%)$ & $4(67 \%)$ & $p<0.05$ \\
\hline BMI & $16.9 \pm 3.2$ & $16.2 \pm 4.4$ & NS \\
\hline \multicolumn{4}{|l|}{ Cardiac anomaly } \\
\hline SVAS (\%) & $19(73 \%)$ & $5(83 \%)$ & NS \\
\hline T-Cho level (mg/ dL) & $167 \pm 36$ & $172 \pm 37$ & NS \\
\hline TG level (mg/ dL) & $61 \pm 27$ & $54 \pm 20$ & NS \\
\hline HDL level & $63 \pm 14$ & $59 \pm 9$ & NS \\
\hline $\operatorname{oxLDL}(n)$ & $16.4 \pm 12.1 \quad(n=11)$ & $21(n=1)$ & \\
\hline MDA-LDL (n) & $77.6 \pm 27.2(n=15)$ & $70.0 \pm 30(n=4)$ & NS \\
\hline Lipo(a) (n) & $18.3 \pm 20.4 \quad(n=26)$ & $26.4 \pm 40.7(n=5)$ & NS \\
\hline $\operatorname{OGTT}(n)$ & $n=16$ & $n=4$ & \\
\hline Impaired GI or DM (\%) & $10(62.5 \%)$ & $2(50 \%)$ & NS \\
\hline Insulinogenic index & $0.89 \pm 0.46$ & $0.78 \pm 0.38$ & NS \\
\hline HOMA-R & $1.62 \pm 0.83$ & $2.07 \pm 0.84$ & NS \\
\hline Plasma rennin level (n) & $4.0 \pm 3.0(n=26)$ & $1.0 \pm 0.8 \quad(n=5)$ & $p<0.05$ \\
\hline Number of hyperreninemia (\%) & $12(46 \%)$ & $0(0 \%)$ & \\
\hline $\begin{array}{l}\text { Plasma aldosterone level (ng/ dL) } \\
\text { (RIA kit) (n) }\end{array}$ & $11.5 \pm 6.0(n=13)$ & $15.7 \pm 3.8(n=2)$ & NS \\
\hline $\begin{array}{l}\text { Plasma aldosterone level }(\mathrm{pg} / \mathrm{mL}) \\
(\mathrm{SPAC})(\mathrm{n})\end{array}$ & $211.3 \pm 91.5(n=13)$ & $71.7 \pm 13.9(n=3)$ & $p<0.05$ \\
\hline Number of hyperaldosteronism (\%) & $12(46 \%)$ & $1(20 \%)$ & NS \\
\hline $\operatorname{ABPM}(n)$ & $n=20$ & $n=4$ & \\
\hline Number of pre-HT and $\mathrm{HT}(\%)$ & $6(30 \%)$ & $2(50 \%)$ & NS \\
\hline IMT (n) & $n=13$ & $n=2$ & \\
\hline Right IMT (mm) & $0.69 \pm 0.11$ & $0.71 \pm 0.11$ & NS \\
\hline Left IMT $(\mathrm{mm})$ & $0.73 \pm 0.11$ & $0.79 \pm 0.13$ & NS \\
\hline Endothelium function $(n)$ & $n=13$ & $n=2$ & \\
\hline FMD (\%) & $7.4 \pm 5.7$ & $2.2 \pm 1.7$ & NS \\
\hline NID (\%) & $18.9 \pm 6.9$ & $11.5 \pm 4.4$ & NS \\
\hline \multicolumn{4}{|c|}{$\begin{array}{l}\text { n: number, BMI: body mass index, T-cho: total cholesterol, TG: triglyceride, HDL: high density lipoprotein, MDA- } \\
\text { LDL: malondialdehyde-modified LDL, OGTT: oral glucose tolerance test, GI: glucose intolerance, DM: diabetes } \\
\text { mellitus, HOMA-IR: homeostasis model assessment insulin resistance, FBS: fasting blood sugar, IMT: flow- } \\
\text { mediated dilatation of the brachial artery, FMD: flow-mediated dilatation of the brachial artery, NID: nitroglycerin- } \\
\text { induced dilatation, ABPM: } 24-h o u r \text { ambulatory blood pressure monitoring, HT: hypertension, Diagonal lines mean } \\
\text { statistical calculation not possible because the number of samples is too small }\end{array}$} \\
\hline
\end{tabular}

n: number, BMI: body mass index, T-cho: total cholesterol, TG : triglyceride, HDL: high density lipoprotein, MDA- LDL: malondialdehyde-modified, LDL, OGTT: oral glucose tolerance test, Gl glucose intolerance, DM: diabetes mellitus, HOMA-R : homeostasis model assessment insulin resistance, FBS: fasting blood sugar, MT: flow- mediated

process [25]. Although obesity is strongly associated with hypercholesterolemia and insulin resistance in children as well as adults, only 1 patient in this study had a BMI of $>22$. The abnormal lipid or glucose metabolism in the rest of the children with WS was not associated with a high BMI. A close relationship between obesity and abnormal lipid/glucose metabolism is not possible with WS. This finding suggests that conditions other than obesity are involved in the high prevalence of CV risk factors in children with WS. Glucose dysregulation is caused by the hemizygosity of syntaxin-1A, a gene located in the WS chromosome region that is believed to be the prime candidate involved in insulin release [24].

\section{Activation of the RAA system and hypertension}

Activation of the RAA system is associated with CV events and progression of arteriosclerosis [26]. In the current study, hypertension and activation of the RAA system were commonly found in the WS patients (Table 1), but there were no significant differences in the renin and aldosterone levels between the hypertensive and nonhypertensive groups. The etiology of hypertension among these patients appears to be multifactorial and potentially involves elastin haploinsufficiency, neutrophil cytosolic factor 1 hemizygosity [27], reduced nicotinamide adenosine dinucleotide phosphate-oxidasemediated oxidative stress [28], an activated RAA system, 
and renovascular disease. In this study, patients with typical deletions exhibited a higher degree of RAA system activity than did patients with atypical deletions. However, the reason behind the high RAA system activity in the typical deletions group remains unclear. Whether microdeletion on chromosome $7 q 11.23$ leads to RAA system activation is also unclear. The precise role of the RAA system in WS should therefore be clarified in future studies.

\section{Brachial artery flow-mediated dilatation and carotid artery intima-media thickness}

In this study, WS patients exhibited high carotid artery IMT, as previously reported [9]. An autopsy of a patient with WS revealed thickened medial tissue with elastic disorganization and a prominence of smooth muscle, not only in the arterial wall of the ascending aorta but also in the arteries of the lungs, kidneys, mesentery, and brain [6, 29]. Generalized arterial wall thickening with secondary lumen narrowing has also been observed in WS [10]. Therefore, this feature is considered a generalized elastin arteriopathy that presents in WS. Thickened medial tissue is thought to be primarily associated with high IMT in these patients; however, ultrasonography cannot differentiate between intimal atherosclerosis and medial hypertrophy.

Low FMD was also observed in the patients in this study. The current study is the first to demonstrate a high prevalence of impaired endothelial function associated with WS. FMD was considered an indicator of vascular endothelial function. Juonala et al. [12] reported that thickened IMT and low FMD are related to CV events. Even in children with diabetes mellitus, obesity, and hyperlipidemia, low FMD reflects impaired endothelial function from early childhood [30-34], and longterm exposure to such risk factors is associated with the development of atherosclerosis later in life [30]. The overall incidence of hypercholesterolemia and hypertension in Japanese school-age children has been reported to be 7 and $1 \%$, respectively [35], lower than the rates observed in our study. Although the number of patients enrolled in our study was small, the results strongly suggest that exposure to $\mathrm{CV}$ risk factors is present from childhood in patients with WS.

Diet and exercise intervention for obese children can reverse the pro-atherosclerotic inflammatory process and preserve vascular function [36]. Good familial support in order to avoid stress, which affects both mental and metabolic states, as well as the appropriate administration of drugs and supplements, may also be useful against the pro-atherosclerotic process in WS [16]. Minoxidil, glucocorticoids, retinoids, vitamin $\mathrm{E}$ and $\mathrm{C}$, and matrix metalloproteinase inhibitors have the potential to upregulate elastin production or prevent its degradation
$[16,25,37-40]$. Nutritional supplements such as $\beta-$ aminopropionitrile (contained in certain legumes), dill extract, and tannic acid may also be effective in preventing elastin arteriopathy [16, 41, 42]. As part of a holistic approach for the management of patients with WS, we encourage patients to follow a traditional low-fat Japanese diet including rice, seaweed, wheat, barley, beans, fish, and vegetables and avoid other animal protein. We also recommend supplementation with vitamin $\mathrm{C}$ and $\mathrm{E}$ and good familial support. Two patients from a similar study experienced a decrease in IMT and an improvement in FMD as a result of this regimen [21].

\section{Conclusion}

$\mathrm{CV}$ risk factors such as hypertension, impaired glucose tolerance, hyperlipidemia, and high IMT are highly prevalent in children with WS. Long-term exposure to these factors may accelerate the development of CV disease in adulthood. WS is a multisystem disorder that requires long-term follow-up, because WS is diagnosed during childhood in most cases. Health care supervisors and pediatricians, who care for children with WS need to be aware of these findings [43]. Screening tests for the early detection of $\mathrm{CV}$ risk factors such as abnormal lipid/glucose metabolism unrelated to obesity and longterm follow-up in WS patients could be helpful for preventing $\mathrm{CV}$ events in adulthood. Further studies are also needed to clarify the etiology of the various risk factors influencing $\mathrm{CV}$ events in these patients.

\section{Abbreviations}

ABP: 24-h ambulatory blood pressure; BMI: Body mass index; BP: Blood pressure; CV: Cardiovascular; IMT: Intima-media thickness; FMD: Flowmediated dilatation; HOMA-IR: Homeostasis model assessment insulin resistance index; Lipo(a): Lipoprotein-a; MDA-LDL: Malondialdehyde-modified LDL; NID: Nitric oxide donor (nitroglycerin)-induced dilatation; OGTT: Oral glucose tolerance test; oxLDL: Oxidized low-density lipoprotein; RAA: Reninangiotensin-aldosterone; SVAS: Supravalvular aortic stenosis; WS: WilliamsBeuren syndrome.

\section{Competing interests}

The authors declare that they have no competing interests.

\section{Authors' contributions}

DT designed the study, analyzed the data, and drafted the manuscript. MT carried out the molecular genetic studies and analyzed the data. YH analyzed the data. YF carried out the molecular genetic studies and analyzed the data. KI designed the study. TN designed the study. RM participated in its design and coordination and helped to draft the manuscript. All authors read and approved the final manuscript.

\section{Acknowledgments}

We would like to thank the patients and families who participated in this study for their cooperation. This work was supported by the Program for Promoting the Establishment of Strategic Research Centers, Special

Coordination Funds for Promoting Science and Technology, Ministry of Education, Culture, Sports, Science and Technology, Japan.

\section{Author details}

'Department of Pediatric Cardiology, Tokyo Women's Medical University, 8-1 Kawada-cho, Shinjuku-ku, Tokyo 162-8666, Japan. ${ }^{2}$ The International Research and Educational Institute for Integrated Medical Sciences (IREIIMS), Tokyo 
Women's Medical University, 8-1 Kawada-cho, Shinjuku-ku, Tokyo 162-8666, Japan. ${ }^{3}$ International Center for Molecular, Cellular, and Immunological Research (IMCIR), Tokyo Women's Medical University, 8-1 Kawada-cho, Shinjuku-ku, Tokyo 162-8666, Japan.

\section{Received: 10 July 2014 Accepted: 9 September 2015} Published online: 17 September 2015

\section{References}

1. Williams JC, Barratt-Boyes BG, Lowe JB. Supravalvular aortic stenosis. Circulation. 1961;24:1311-8.

2. Ji C, Yao D, Chen W, Li M, Zhao Z. Adaptive behavior in Chinese children with Williams syndrome. BMC Pediatr. 2014;14:90

3. Ewart AK, Morris CA, Atkinson D, Jin W, Sternes K, Spallone P, et al. Hemizygosity at the elastin locus in a developmental disorder, Williams syndrome. Nat Genet. 1993;5(1):11-6.

4. Kotzot D, Bernasconi F, Brecevic L, Robinson WP, Kiss P, Kosztolanyi G, et al. Phenotype of the Williams-Beuren syndrome associated with hemizygosity at the elastin locus. Eur J Pediatr. 1995:154(6):477-82.

5. Pober BR, Morris CA. Diagnosis and management of medical problems in adults with Williams-Beuren syndrome. Am J Med Genet C Semin Med Genet. 2007;145(3):280-90

6. Kimura K, Hirota H, Nishikawa T, Ishiyama S, Imamura S, Korenberg JR, et al. Chromosomal deletion and Phenotype correlation in patients with Williams syndrome. In: Edward B, Clark M, Makoto Nakazawa MD, Atsuyoshi Takao $M D$, editors. Etiology and morphogenesis of congenital heart disease: twenty years of progress in genetics and developmental biology. edn. Armonk, NY: Futura Publishing; 2000. p. 381-4.

7. American Diabetes Association. Screening for type 2 diabetes. Diabetes Care. 2004;27 Suppl 1:S11-14.

8. National High Blood Pressure Education Program Working Group. The fourth report on the diagnosis, evaluation, and treatment of high blood pressure in children and adolescents. Pediatrics. 2004;114(2 Suppl 4th Report):555-76.

9. Sadler LS, Gingell R, Martin DJ. Carotid ultrasound examination in Williams syndrome. J Pediatr. 1998;132(2):354-6.

10. Rein AJ, Preminger TJ, Perry SB, Lock JE, Sanders SP. Generalized arteriopathy in Williams syndrome: an intravascular ultrasound study. J Am Coll Cardiol. 1993;21(7):1727-30

11. Bohm B, Hartmann K, Buck M, Oberhoffer R. Sex differences of carotid intima-media thickness in healthy children and adolescents. Atherosclerosis. 2009;206(2):458-63.

12. Juonala M, Viikari JS, Laitinen T, Marniemi J, Helenius H, Ronnemaa T, et al. Interrelations between brachial endothelial function and carotid intimamedia thickness in young adults: the cardiovascular risk in young Finns study. Circulation. 2004;110(18):2918-23.

13. Collins 2nd RT, Kaplan P, Somes GW, Rome JJ. Long-term outcomes of patients with cardiovascular abnormalities and williams syndrome. Am J Cardiol. 2010;105(6):874-8.

14. Dridi SM, Foucault Bertaud A, Igondjo Tchen S, Senni K, Ejeil AL, Pellat B, et al. Vascular wall remodeling in patients with supravalvular aortic stenosis and Williams Beuren syndrome. J Vasc Res. 2005;42(3):190-201.

15. Ingelfinger JR, Newburger JW. Spectrum of renal anomalies in patients with Williams syndrome. J Pediatr. 1991;119(5):771-3.

16. Pober BR, Johnson M, Urban Z. Mechanisms and treatment of cardiovascular disease in Williams-Beuren syndrome. J Clin Invest. 2008;118(5):1606-15.

17. Cherniske EM, Carpenter TO, Klaiman C, Young E, Bregman J, Insogna K, et al. Multisystem study of 20 older adults with Williams syndrome. Am J Med Genet A. 2004;131 A(3):255-64.

18. Bedeschi MF, Bianchi V, Colli AM, Natacci F, Cereda A, Milani D, et al. Clinical follow-up of young adults affected by Williams syndrome: Experience of 45 Italian patients. Am J Med Genet A. 2011;155(2):353-9.

19. Amenta S, Sofocleous C, Kolialexi A, Thomaidis L, Giouroukos S, Karavitakis E, et al. Clinical manifestations and molecular investigation of 50 patients with Williams syndrome in the Greek population. Pediatr Res. 2005;57(6):789-95.

20. Juonala M, Magnussen CG, Venn A, Dwyer T, Burns TL, Davis PH, et al. Influence of age on associations between childhood risk factors and carotid intima-media thickness in adulthood: the Cardiovascular Risk in Young Finns Study, the Childhood Determinants of Adult Health Study, the Bogalusa
Heart Study, and the Muscatine Study for the International Childhood Cardiovascular Cohort (i3C) Consortium. Circulation. 2010;122(24):2514-20.

21. Nadal-Ginard BTK. Prevalence of risk factors of cardiovascular events, and the effects of a natural food diet, ascorbate and vitamine $E$ to prevent the progression of arteriopathy in Williams syndrome. Tokyo: International Research and Educational instutute for Integrated medical Sciences (IREIMS) Tokyo Women's Medical University; 2007.

22. Esterbauer H, Schmidt R, Hayn M. Relationships among oxidation of lowdensity lipoprotein, antioxidant protection, and atherosclerosis. Adv Pharmacol. 1997;38:425-56.

23. Steinberg D, Parthasarathy S, Carew TE, Khoo JC, Witztum JL. Beyond cholesterol. Modifications of low-density lipoprotein that increase its atherogenicity. N Engl J Med. 1989;320(14):915-24.

24. Pober BR, Wang E, Caprio S, Petersen KF, Brandt C, Stanley T, et al. High prevalence of diabetes and pre-diabetes in adults with Williams syndrome. Am J Med Genet C Semin Med Genet. 2010;154C(2):291-8.

25. Fulop Jr T, Larbi A, Fortun A, Robert $L$, Khalil A. Elastin peptides induced oxidation of LDL by phagocytic cells. Pathol Biol (Paris). 2005;53(7):416-23.

26. Vantrimpont $P$, Rouleau JL, Ciampi A, Harel F, de Champlain J, Bichet D, et al. Two-year time course and significance of neurohumoral activation in the Survival and Ventricular Enlargement (SAVE) Study. Eur Heart J. 1998;19(10):1552-63.

27. Del Campo M, Antonell A, Magano LF, Munoz FJ, Flores R, Bayes M, et al. Hemizygosity at the NCF1 gene in patients with Williams-Beuren syndrome decreases their risk of hypertension. Am J Hum Genet. 2006;78(4):533-42.

28. Campuzano V, Segura-Puimedon M, Terrado V, Sanchez-Rodriguez C, Coustets M, Menacho-Marquez $\mathrm{M}$, et al. Reduction of NADPH-oxidase activity ameliorates the cardiovascular phenotype in a mouse model of Williams-Beuren Syndrome. PLoS Genet. 2012;8(2):e1002458.

29. Kawai M, Nishikawa T, Tanaka M, Ando A, Kasajima T, Higa T, et al. An autopsied case of Williams syndrome complicated by moyamoya disease. Acta Paediatr Jpn. 1993;35(1):63-7.

30. Raitakari OT, Juonala M, Kahonen M, Taittonen L, Laitinen T, Maki-Torkko N, et al. Cardiovascular risk factors in childhood and carotid artery intimamedia thickness in adulthood: the Cardiovascular Risk in Young Finns Study. JAMA. 2003;290(17):2277-83.

31. Aggoun Y, Farpour-Lambert NJ, Marchand LM, Golay E, Maggio AB, Beghetti M. Impaired endothelial and smooth muscle functions and arterial stiffness appear before puberty in obese children and are associated with elevated ambulatory blood pressure. Eur Heart J. 2008;29(6):792-9.

32. Babar GS, Zidan H, Widlansky ME, Das E, Hoffmann RG, Daoud M, et al. Impaired endothelial function in preadolescent children with type 1 diabetes. Diabetes Care. 2011;34(3):681-5.

33. Yilmazer MM, Tavli V, Carti OU, Mese T, Guven B, Aydin B, et al. Cardiovascular risk factors and noninvasive assessment of arterial structure and function in obese Turkish children. Eur J Pediatr. 2010;169(10):1241-8.

34. Jarvisalo MJ, Raitakari M, Toikka JO, Putto-Laurila A, Rontu R, Laine S, et al. Endothelial dysfunction and increased arterial intima-media thickness in children with type 1 diabetes. Circulation. 2004;109(14):1750-5.

35. Yanagi H, Hamaguchi H, Shimakura Y, Hirano C, Takita H, Tsuchiya S, et al. Cardiovascular risk factors among Japanese school-age children: a screening system for children with high risk for atherosclerosis in Ibaraki, Japan. Nihon Koshu Eisei Zasshi. 1993;40(12):1120-8.

36. Kelishadi R, Hashemi M, Mohammadifard N, Asgary S, Khavarian N. Association of changes in oxidative and proinflammatory states with changes in vascular function after a lifestyle modification trial among obese children. Clin Chem. 2007;54(1):147-53.

37. McGowan SE, Doro MM, Jackson SK. Endogenous retinoids increase perinatal elastin gene expression in rat lung fibroblasts and fetal explants. Am J Physiol. 1997;273(2 Pt 1):L410-416.

38. Pierce RA, Mariencheck WI, Sandefur S, Crouch EC, Parks WC. Glucocorticoids upregulate tropoelastin expression during late stages of fetal lung development. Am J Physiol. 1995;268(3 Pt 1):L491-500.

39. Tsoporis J, Keeley FW, Lee RM, Leenen FH. Arterial vasodilation and vascular connective tissue changes in spontaneously hypertensive rats. J Cardiovasc Pharmacol. 1998;31(6):960-2.

40. Sluijter JP, de Kleijn DP, Pasterkamp G. Vascular remodeling and protease inhibition-bench to bedside. Cardiovasc Res. 2006;69(3):595-603.

41. Tinker D, Rucker RB. Role of selected nutrients in synthesis, accumulation, and chemical modification of connective tissue proteins. Physiol Rev. 1985;65(3):607-57. 
42. Jimenez F, Mitts TF, Liu K, Wang Y, Hinek A. Ellagic and tannic acids protect newly synthesized elastic fibers from premature enzymatic degradation in dermal fibroblast cultures. J Invest Dermatol. 2006;126(6):1272-80.

43. American Academy of Pediatrics. American Academy of Pediatrics: Health care supervision for children with Williams syndrome. Pediatrics. 2001;107(5):1192-204.

Submit your next manuscript to BioMed Central and take full advantage of:

- Convenient online submission

- Thorough peer review

- No space constraints or color figure charges

- Immediate publication on acceptance

- Inclusion in PubMed, CAS, Scopus and Google Scholar

- Research which is freely available for redistribution 